\title{
Composite Mesh Electrodes with Immobilized Bacteria for Bio-Batteries
}

\author{
Siddharth Suresh, Richard W. Evitts, Glyn F. Kennell \\ Department of Chemical and Biological Engineering, University of Saskatchewan, Saskatoon, Canada \\ Email: sis394@mail.usask.ca,Richard.Evitts@usask.ca, Glyn.Kennell@usask.ca
}

Received 6 November 2015; accepted 16 January 2016; published 19 January 2016

Copyright (C) 2016 by authors and Scientific Research Publishing Inc.

This work is licensed under the Creative Commons Attribution International License (CC BY). http://creativecommons.org/licenses/by/4.0/

(c) $\underset{\mathrm{EY}}{\mathrm{E}}$ Open Access

\begin{abstract}
An anode was constructed using a novel technique and subsequently tested in a bio-battery. The anode comprised of a composite electrode coated with immobilized bacteria. The immobilized bacteria used in this study were Escherichia coli K-12. The composite electrode contained three layers: a $304 \mathrm{~L}$ stainless steel mesh base, an electro-polymerized layer of pyrrole, and an electropolymerized layer of methylene blue. The bacteria were immobilized utilizing a technique incorporating a carbon nanoparticle and Teflon $^{\mathrm{TM}}$ emulsion. The composite electrode combined with immobilized bacteria was examined whilst incorporated into the anodic chamber of a bio-battery. Different tests were conducted, including Electrochemical Impedance Spectroscopy. Results from these tests were compared with data obtained from alternate configurations and values from the open literature. The maximum power density generated by the composite electrode with immobilized bacteria whilst incorporated into the anodic chamber of a bio-battery was $378 \mathrm{~mW} / \mathrm{m}^{2}$. Results demonstrate this composite anode configuration with immobilized bacteria produced approximately $69 \%$ more power density and $53 \%$ more current density than alternate electrode configurations with bacteria suspended in solution. Also, it was found that a significant portion of the bio-battery's resistance to charge transfer occurred at the surface of the anode and this resistance was lowered by $51 \%$ through bacteria immobilization.
\end{abstract}

\section{Keywords}

Stainless Steel Mesh, Immobilized Mediator, Bacteria, Photosynthetic Algae, Battery, Electrochemical Impedance Spectroscopy

\section{Introduction}

Microbial Fuel Cells (MFC) and bio-batteries have gained interest over the past decade and may provide a po- 
tential source of energy through the conversion of chemical energy from organic sources into electrical energy using microbes [1]. MFCs have also been used for the purification of wastewater using bacteria [2]. For the technologies investigated in this paper it is assumed that MFCs and bio-batteries may appear to be identical except that in a MFC the substrate is replenished and in a bio-battery it is not [3]. Although dual chambered MFCs have been studied over the past few decades multiple aspects must still be investigated. One such aspect is the development of novel electrodes that are cost effective and efficient. For electrode construction, noble metals such as platinum and gold provide good results, but they are expensive. Additionally, if the mediators used in MFCs are immobilized on the electrode this can reduce the cost of replenishing mediators in solution. Mediators often improve the efficiency of MFCs. Also, it has been shown that bacteria immobilization on the surface of an electrode may reduce the start-up time of MFCs or Bio-Batteries [3]. For non exo-electrogenic bacteria that require mediators for the transfer of electrons to the electrodes, it is possible that the application of bacteria and mediator immobilization may reduce the electrochemical resistance caused due to the transfer of charges from the bacterial cells to the electrode by the mediator.

One of the primary benefits of using a mediator in a MFC is its ability to lower the anode potential compared to mediator-less MFC, which lose appreciable energy during intracellular electron transfer [3]. Even though MFCs with soluble mediators have better performance than mediator-less fuel cells, they have technical difficulties, including the secondary contamination of effluent by the mediators. Also, they are expensive for large scale operations as the mediators must be replenished often. Some of the commonly employed mediators are methylene blue, neutral red, thionin, and 1, 2 hydroxynapthaquinone. Recently polyviologen was immobilized on a carbon cloth anode and produced a power density as high as $540 \mathrm{~mW} / \mathrm{m}^{2}$ and a current density of $1.7 \mathrm{~A} / \mathrm{m}^{2}$ in a single chambered cell with air cathode [4]. Prieto-Simón and Fàbregas analysed the influence of mediators by researching the variations between mediators in epoxy composites, mediators suspended in solution, and mediators adsorbed or polymerized on electrode surfaces in biosensors. They found that mediators polymerized on electrode surfaces were more suitable due to their sustainable and reproducible results [5]. Qaio and colleagues used nickel foam anodes coated with CNT-polyaniline paste and E. coli K-12 to achieve a significant increase in power density (maximum power density of $42 \mathrm{~mW} / \mathrm{m}^{2}$ ) [6]. Ming and colleagues used E. coli $K-12$ bio-film taming technique to achieve a 56\% increase in current density and almost 2-fold increase in power density compared to the parental E. coli K-12 [7].

Generally, carbonaceous materials are widely employed owing to their good bio compatibility, chemical stability, low cost and high conductivity [8]-[11]. Park and colleagues used $\mathrm{Mn}^{4+}$-graphite anodes and $\mathrm{Fe}^{3+}$-graphite cathodes with E. coli K-12 to achieve maximum current and power densities of $325 \mathrm{~mA} / \mathrm{m}^{2}$ and $91 \mathrm{~mW} / \mathrm{m}^{2}$ respectively [10]. Carbon paper was used as electrodes in two different setups containing E. coli K-12 as anode catalyst and neutral red as mediator to achieve a maximum power density of $8 \mathrm{~mW} / \mathrm{m}^{2}$ [11]. Graphite electrodes with neutral red as mediator and E. coli K-12 produced a maximum current density of $31 \mathrm{~mA} / \mathrm{m}^{2}$ [12]. However, these carbonaceous electrodes are quite brittle, thereby leading to the search for stronger alternatives. Stainless steel (SS) electrodes have not been studied as extensively as the carbonaceous electrodes but have only been shown to work effectively as cathode electrodes [13] and under marine conditions in seafloor microbial fuel cells driven by the potential difference between anaerobic and aerobic regions of sea bed and sea surface respectively [14]. Hoffman et al. compared a composite electrode (formed from a stainless steel rod coated with polypyrrole and methylene blue) with bare graphite rod electrodes in an E. coli K-12 based MFC and determined that the composite electrodes produced a 6-fold increase in power density [15].

Bacteria immobilization directly on an electrode, instead of bio-film formation, was studied by researchers in the past. Yuan et al. immobilized Proteus vulgaris on carbon paper electrodes in a mediator-less setup and achieved a maximum power density of $269 \mathrm{~mW} / \mathrm{m}^{2}$ [16]. It was determined that bacteria immobilization directly on the electrode would reduce the start-up time of the fuel cell. For the work in this paper, it was hypothesised that mediator and bacteria immobilization on the anode would facilitate the transport of charge from the bacterial cells to the anode, thereby reducing the anodic charge transfer resistance.

\section{Materials and Methods}

\subsection{Microbial Cultures and Medium}

Escherichia coli K-12, used in the anode chamber, was a pure culture obtained from the American Type Culture Collection. The cultures were grown aerobically in Erlenmeyer flasks placed in a shaker at $37^{\circ} \mathrm{C}$ and $250 \mathrm{rpm}$ 
for 24 hours. The medium used for the growth contained: $10.00 \mathrm{~g} / \mathrm{L}$ of tryptone, $10.00 \mathrm{~g} / \mathrm{L} \mathrm{of} \mathrm{NaCl,} 5.00 \mathrm{~g} / \mathrm{L}$ of yeast extract and $20.00 \mathrm{~g} / \mathrm{L}$ of glucose. The medium and flasks were sterilized in an autoclave before culturing the bacteria.

\subsection{Electrochemical Equipment}

A Gamry ${ }^{\mathrm{TM}}$ Reference 600 potentiostat along with PHE $200^{\mathrm{TM}}$ software was used for electro polymerization of pyrrole and mediator, measuring open circuit potentials, and obtaining polarization curves. The potentiostat was calibrated using a standard cell in a Faraday's cage before running experiments. A relatively slow potential sweep of $0.15 \mathrm{mV} / \mathrm{s}$ was used to generate the voltage-current curves. Open circuit potentials were recorded between the anode and cathode electrodes. A Gamry ${ }^{\mathrm{TM}}$ Interface 1000 potentiostat was used for the Electrochemical Impedance Sectroscopy (EIS) analysis of fuel cells and the data was fit using specific equivalent circuit models.

\subsection{Composite Electrode Preparation}

Stainless steel mesh of $2.54 \mathrm{~cm}$ diameter was obtained from McMaster-Carr, Canada. The meshes were washed with acetone to remove any metal fragments that may have interfered with polymerization. The method used for electro-polymerization of pyrrole and mediator on the mesh was similar to the method used by Godwin and Evitts [17] with a slight variation in solution concentration due to the geometry and morphology of stainless steel mesh. Polymerization of pyrrole on the stainless steel mesh electrodes was conducted galvanostatically, at a current density of $6 \mathrm{~mA} / \mathrm{m}^{2}$ in a three electrode cell. The cell consisted of a working electrode, graphite counter electrode, and saturated calomel reference electrode. The solution contained $0.350 \mathrm{~mol} / \mathrm{L}$ pyrrole, 0.080 $\mathrm{mol} / \mathrm{L}$ salicylate and small amounts of orthophosphoric acid to maintain the $\mathrm{pH}$ at 4.2. The polymerization time required was approximately 180 seconds [18].

Subsequently, the polypyrrole coated electrode was immersed in a solution containing $0.001 \mathrm{~mol} / \mathrm{L}$ methylene blue, $0.1 \mathrm{~mol} / \mathrm{L}$ potassium nitrate, $0.025 \mathrm{~mol} / \mathrm{L}$ sodium borate, with the $\mathrm{pH}$ adjusted to 9.5 using potassium hydroxide in a cell similar to that used for pyrrole polymerization, for methylene blue electro-deposition. Ten cyclic voltammetry sweeps between $-0.5 \mathrm{~V}_{\mathrm{SCE}}$ and $1.05 \mathrm{~V}_{\mathrm{SCE}}$ were used to form the polymethylene blue layer. These voltage limits were chosen because below $-0.5 \mathrm{~V}_{\mathrm{SCE}}$ the doping ions (salicylate) leave the solution and insulate the polymer layer while above $1.05 \mathrm{~V}_{\mathrm{SCE}}$ over-oxidation occurs with degradation of the film [18]. The polymerization of methylene blue can be confirmed by a purple colour on the electrode while the polypyrrole coated electrode is black [3]. The electrodes were stored in reverse osmosis water until use.

\subsection{Carbon Nanoparticle-Bacteria Paste Preparation}

The methodology for bacteria immobilization on the composite electrode was modified from the method used by Yuan et al. [4]. In this method, $0.3 \mathrm{~g}$ of Vulcan XC-72 R (carbon nanoparticles) was homogeneously spread in $10 \mathrm{ml}$ of water using ultrasonication. The cultured bacteria were harvested from the liquid culture through centrifugal action (8000 rpm for 10 minutes) and introduced into the container containing carbon particles. This solution was stirred for 2 minutes and $1 \mathrm{ml}$ of Teflon ${ }^{\mathrm{TM}}$ emulsion (Teflon, PTFE 3859, DuPont, USA) containing $60 \%$ (by weight) resin in water was mixed with the carbon nanoparticles to form the Carbon Nanoparticle and bacteria paste (CNP-bacteria paste). The final solution was stirred for at least 2 minutes until a sticky CNP-bacteria suspension was obtained which was then evenly applied on both the sides of the composite mesh electrode.

Different configurations of electrodes were constructed for analysis; some composite electrodes were covered with CNP paste only, and some composite electrodes were covered with CNP-bacteria paste. Figure 1 shows SEM images of these electrodes covered with CNP paste, (a) without, and (b) with, Escherichia coli K-12 bacteria. Each bacterium, which is rod shaped and white in the figure, can be clearly seen attached to the carbon particles in the lower right-hand portion of Figure 1(b). Figure 1(a) does not show any white rod shaped bacterium.

\subsection{Experimental Set-Up}

Different configurations of electrodes were incorporated into a conventional H-type bio-battery and tested. The H-type configuration of the bio-battery contained anode, cathode, working electrode, counter electrode, reference 


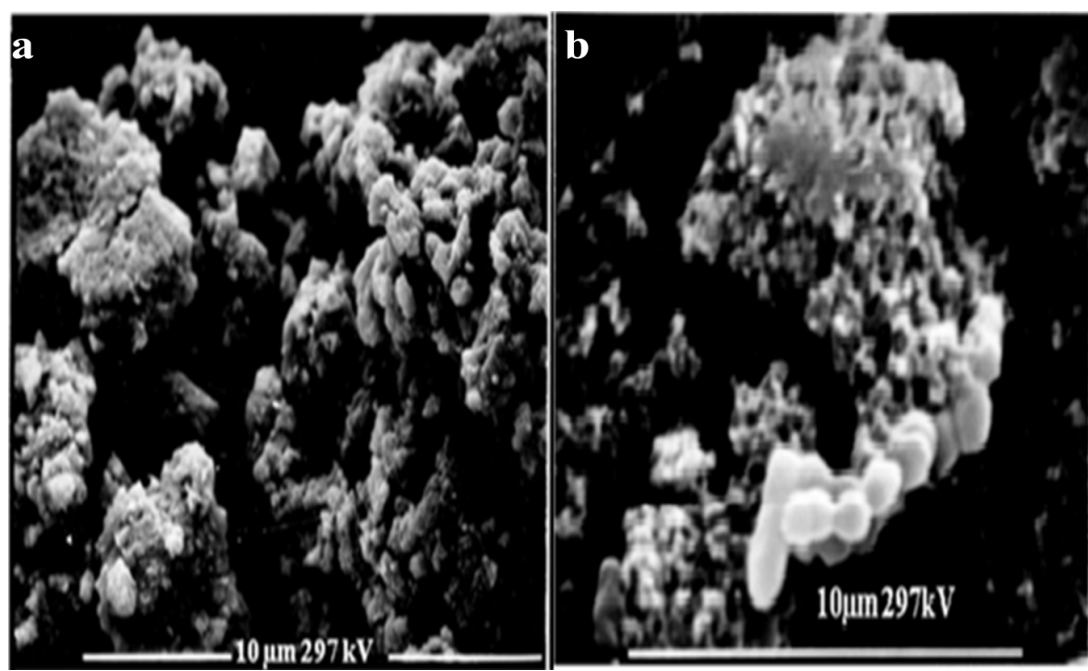

Figure 1. SEM images of composite electrodes (a) with only carbon paste and (b) with carbon paste and bacteria [18].

electrode, and potentiostat system, where both the anodic and cathodic chambers had a capacity of $600 \mathrm{ml}$. Both of the chambers were filled with $500 \mathrm{ml}$ of solution and separated with a Nafion ${ }^{\mathrm{TM}}$ proton exchange membrane with an approximate surface area of $5 \mathrm{~cm}^{2}$. The Nafion ${ }^{\mathrm{TM}}$ membrane was pretreated by boiling for 1 hour in each of two solutions: $3 \% \mathrm{H}_{2} \mathrm{O}_{2}$ de-ionized water and $0.5 \mathrm{M} \mathrm{H}_{2} \mathrm{SO}_{4}$. The cathode chamber was filled with $0.050 \mathrm{M}$ potassium ferricyanide and $0.050 \mathrm{M}$ phosphate buffer solution to maintain an approximate $\mathrm{pH}$ of 7 . The anode chamber contained L-B medium with buffer solution (10 g/L sodium bicarbonate, $8.5 \mathrm{~g} / \mathrm{L}$ potassium di-hydrogen phosphate) and $20 \mathrm{~g} / \mathrm{L}$ glucose at a $\mathrm{pH}$ of approximately 6.5. Sterile graphite and saturated calomel reference electrodes were inserted into the cathode chamber while the electrodes to be examined were inserted into the anode chamber. Both chambers were sealed with insulation tape. Nitrogen was sparged into the anode chamber in order to maintain anaerobic conditions. Magnetic stir bars were used in both chambers to prevent settling and maintain a uniform composition.

\subsection{Fuel Cell Performance Analysis}

The bio-batteries were analyzed by measuring and plotting polarization and power density curves, substrate concentration analysis and recording the impedance spectra for determining the internal resistances. All biobattery configurations were operated at room temperature and the electrode performance was tested by running polarization experiments once the open circuit potentials reached steady state. The obtained current values were divided by the 2-D projected surface area $\left(5.1 \mathrm{~cm}^{2}\right)$ of the anode to obtain the current density. Polarization experiments were run on consecutive days at a potential sweep of $0.15 \mathrm{mV} / \mathrm{s}$ between the measured open circuit and closed circuit potential ranges and their average was plotted with standard deviation error bars. Glucose (substrate) concentration was analyzed using a glucose analyzer to confirm microbial growth and bio-electrochemical activity.

Electrochemical Impedance Spectroscopy (EIS) measurements were taken at the stable open circuit voltage (maximum cell potential) in a two-electrode mode with the anode being the working electrode and cathode as the counter and reference electrode, as previously described [10] [19]. The impedance measurements were performed when the power generation reached the maximum, determined by polarization measurements [20]. A small alternating current signal with an amplitude of $10 \mathrm{mV}$ and a frequency range of $100 \mathrm{kHz}$ to $0.1 \mathrm{~Hz}$ was applied. The anodic impedance spectra were determined by connecting the anode as the working electrode and the cathode as the counter electrode with the saturated calomel reference electrode placed in the anode compartment. The ohmic resistance contribution of the membrane was determined by subtracting the anodic impedance spectra from the combined impedance spectra of the anode and membrane, which was recorded with the anode as the working electrode and cathode as the counter electrode with saturated calomel reference electrode placed in the cathode compartment [21]. 
The equivalent circuit shown in Figure 2 was used to fit the impedance data using Gamry ${ }^{\mathrm{TM}}$ Echem Analyst software to determine the values of the MFC ohmic resistance, charge transfer resistance, and diffusion resistance. This equivalent circuit model is commonly employed for dual chambered MFCs [20] and is used to determine the charge transfer contributions of anode and cathode separately along with the ohmic resistance. $R_{c}$ and $R_{a}$ represent the individual charge transfer resistances of the cathode and anode respectively with $Y_{o c}$ and $Y_{o}$ their associated constant phase elements. The overall internal resistance is the sum of $\mathrm{Ru}, \mathrm{Ra}$ and $\mathrm{Rc}$ while the overall charge transfer resistance is the sum of $R_{a}$ and $R_{c}$.

\section{Results and Discussion}

\subsection{Polarization Curves}

Composite electrodes with a CNP-bacteria paste were incorporated into the anodic chamber of the bio-battery and tested. Polarization curves may be used to determine the performance and the internal resistance of a MFC [3]. Polarization plots with a slow potential sweep of $0.15 \mathrm{mV} / \mathrm{s}$ were conducted. These slow potential sweeps allowed the scan to reach steady state at each data point and provided a good representation of the voltage-current behavior in a manner similar to that conducted by Hoffman et al. [3]. Figure 3 shows the cyclic voltammetry plots for two configurations: a bio-battery anode incorporating a composite electrode with CNP-bacteria paste (immobilized bacteria) and composite electrode with bacteria suspended in the solution. Figure 3 shows the composite electrode with immobilized bacteria (CNP-bacteria paste) setup produced a higher short circuit current than the composite electrode with bacteria suspended in the solution.

Figure 4 shows the polarization curve for a composite electrode with immobilized bacteria (CNP-bacteria paste) compared with the polarization curves for composite electrodes in other configurations. These alternate configurations include: Case I, a composite electrode with immobilized CNP paste and bacteria suspended in solution, and Case II, a composite electrode with bacteria suspended in solution. The composite electrode with immobilized bacteria (CNP-bacteria paste) produced an average short circuit current density of $1506 \mathrm{~mA} / \mathrm{m}^{2}$, almost a 53\% increase when compared with current densities of Case I and Case II. Moreover, Case I produced approximately $13 \%$ more current density than Case II. This may be due to the carbon nanoparticles facilitating better electron transfer by increasing the surface area for bacterial adhesion.

\subsection{Power Density Curves}

A power density curve displays the maximum power output from a system with its corresponding current density. Figure 5 shows the power density curves of a composite electrode with immobilized bacteria (CNP-bacteria

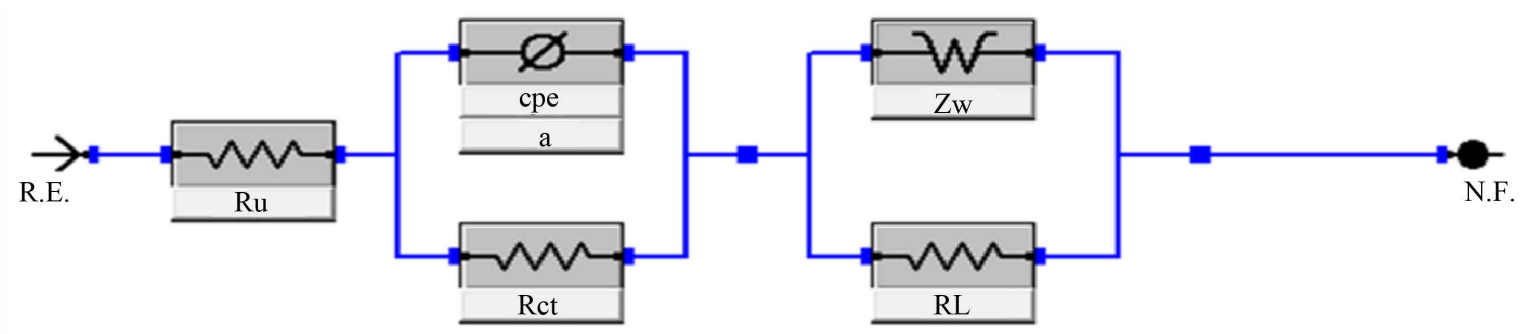

(a)

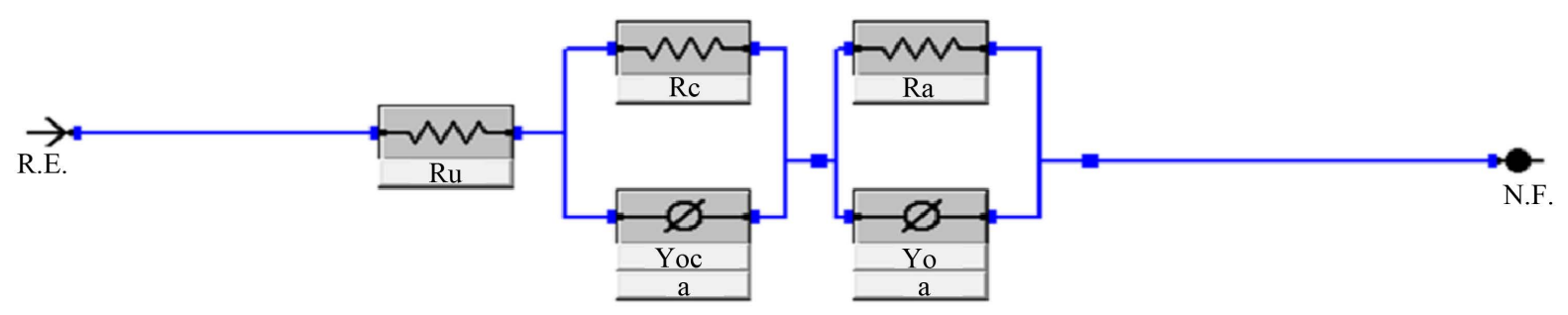

(b)

Figure 2. Model 1 (a) and Model 2 (b) for EIS data fit [18]. 


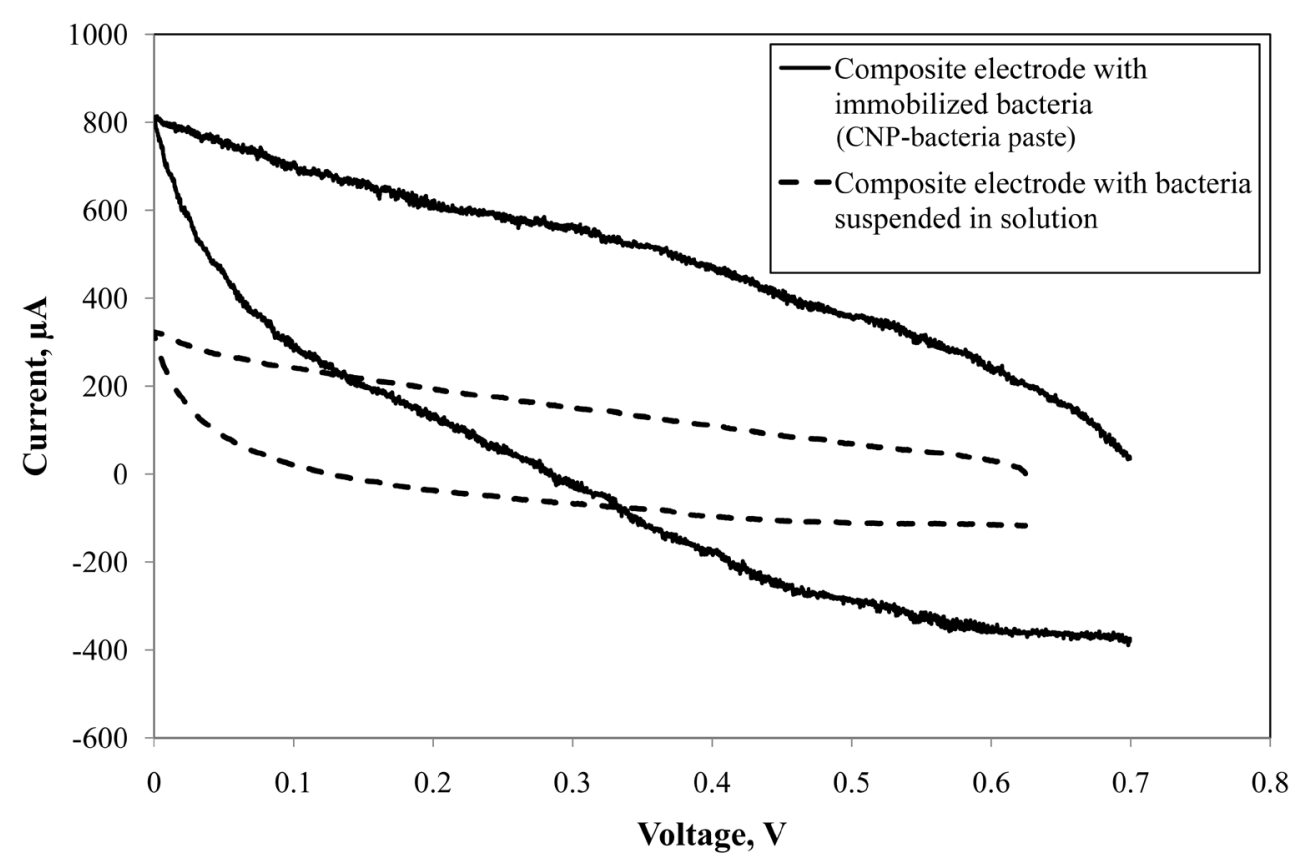

Figure 3. Cyclic voltammetry plots for bio-batteries with immobilized (CNP-bacteria paste) and suspended bacteria [18].

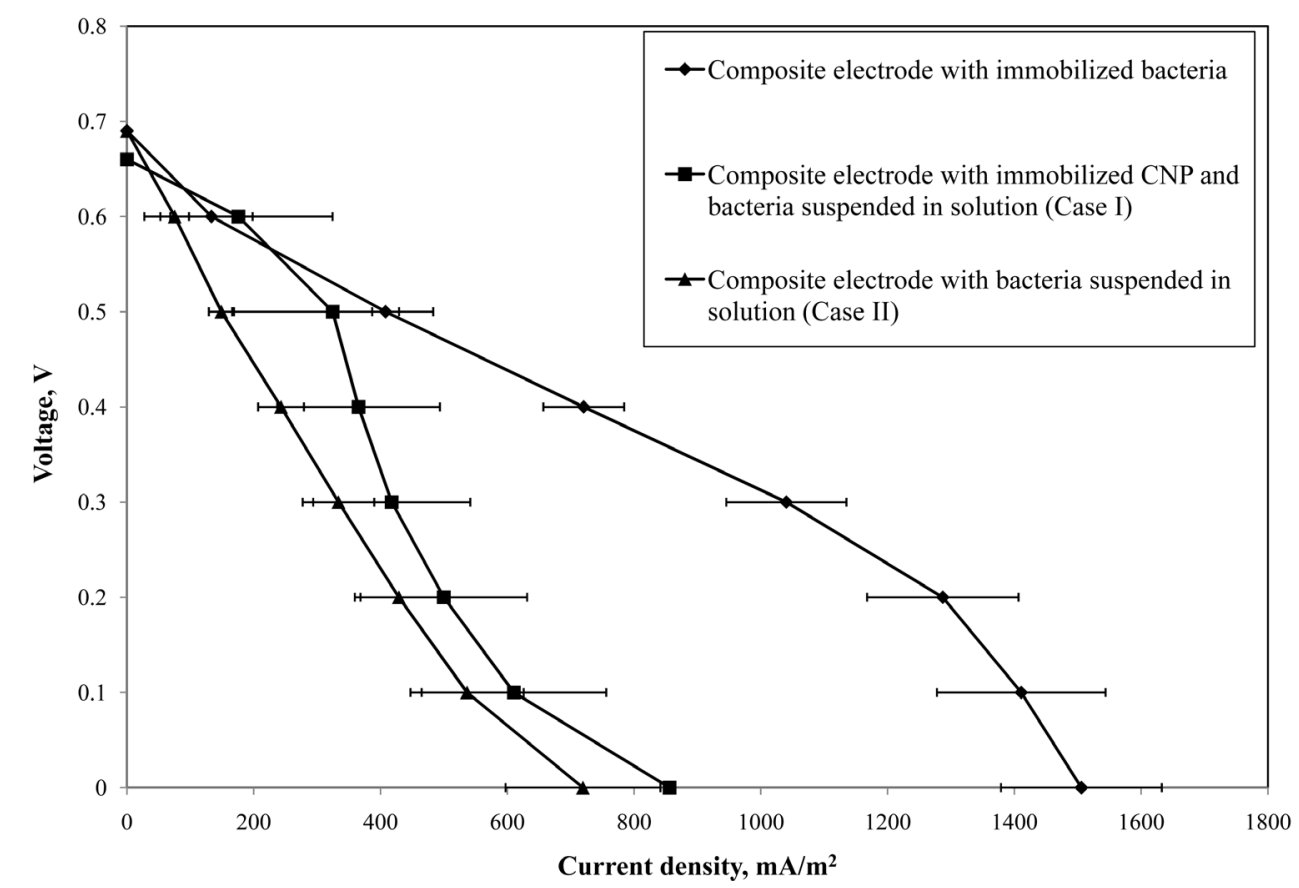

Figure 4. Polarization curves of composite electrode with immobilized bacteria compared with other composite electrode configurations [18].

paste) and other electrode configurations. The two other configurations are: Case I, a composite electrode with immobilized CNP paste and bacteria suspended in solution, and Case II, a composite electrode with bacteria suspended in solution. The composite electrode with immobilized bacteria (CNP-bacteria paste) achieved an average power density of $331 \mathrm{~mW} / \mathrm{m}^{2}$. This is almost $69 \%$ more than the other configurations with suspended bacteria (Cases I and II). 


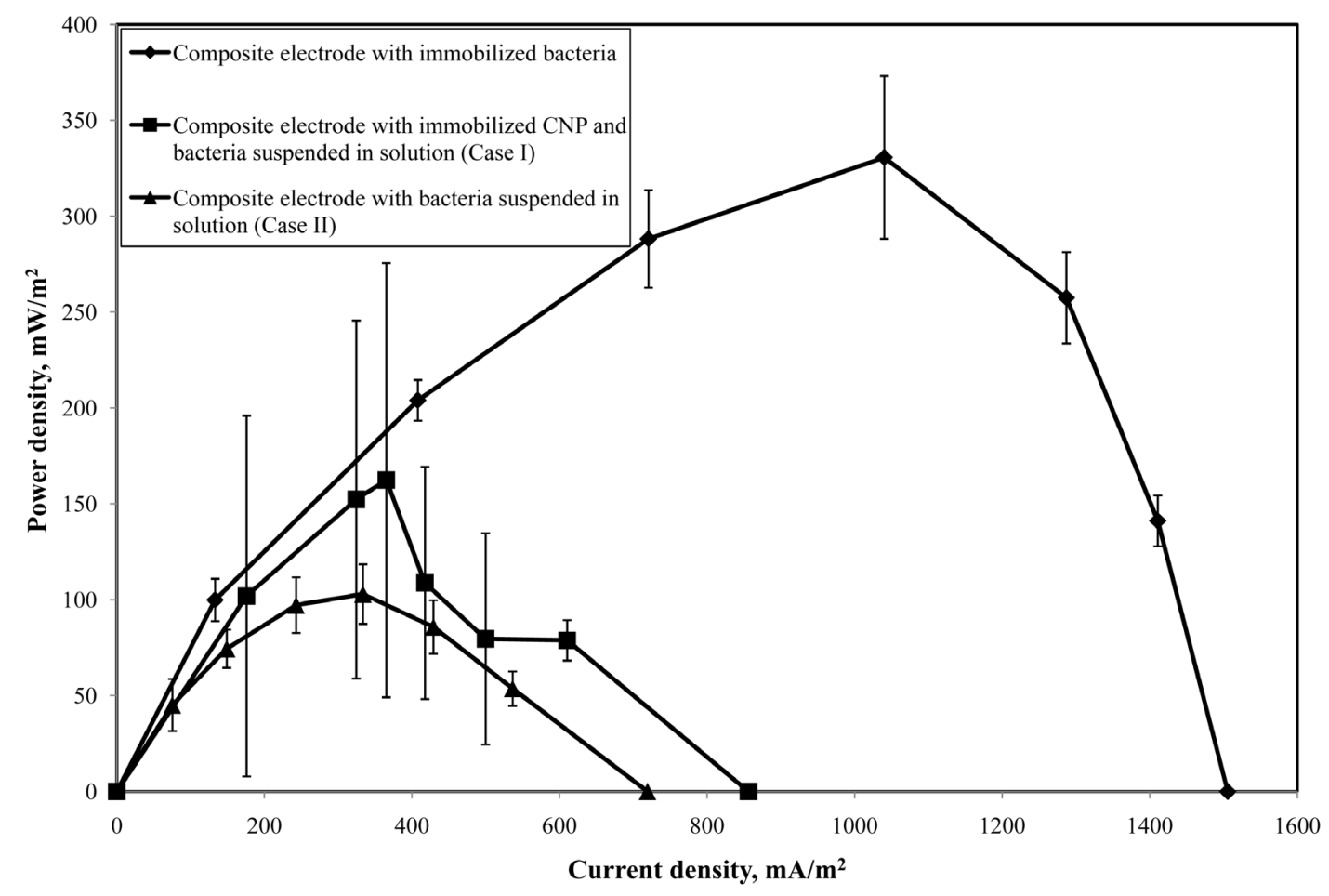

Figure 5. Power density curves of composite electrode with immobilized bacteria compared with other composite electrode configurations [18].

\subsection{Effect of Teflon ${ }^{\mathrm{TM}}$ and CNP Concentration on MFC Performance}

The amount of Teflon ${ }^{\mathrm{TM}}$ added to bind the carbon nanoparticles and bacteria greatly affects the performance of the MFC. Higher concentrations of Teflon ${ }^{\mathrm{TM}}$ will insulate the electrode surface to charge transfer, while lower concentrations will not bind the bacteria and carbon nanoparticles sufficiently [4]. Figure 6 shows the change in power density with various amounts of Teflon ${ }^{\mathrm{TM}}$ added to the $10 \mathrm{ml}$ of CNP-bacteria paste for application on the composite anode. As seen in the figure, $0.5 \mathrm{ml}$ and $1.5 \mathrm{ml}$ of Teflon ${ }^{\mathrm{TM}}$ produced lesser power than $1.0 \mathrm{ml}$ of Teflon $^{\mathrm{TM}}$. This data is in accordance with previous research conducted using Proteus vulgaris and Teflon ${ }^{\mathrm{TM}}$ [4].

The electrode performance was also studied by varying the amounts of CNP. $0.2 \mathrm{~g}, 0.3 \mathrm{~g}$, and $0.4 \mathrm{~g}$ of Vulcan XC-72R carbon nanoparticles in $10 \mathrm{ml}$ of water were used to create the CNP-bacteria paste and applied to the surface of the composite electrode. Figure 7 shows the average power density plots for various CNP amounts. As seen from the figure, the maximum power density using $0.2 \mathrm{~g}$ of CNP was slightly lower than maximum power densities using 0.3 and $0.4 \mathrm{~g}$ of CNP, but not significantly so. Also, the current densities were generally similar. This confirms that the inner portion of CNP-bacteria paste had little impact on the power production and only the CNP and bacteria located near the surface increased power [4]. For this study, using E. coli K-12 and composite mesh electrodes, $0.3 \mathrm{~g}$ of CNP with $1 \mathrm{~mL}$ Teflon ${ }^{\mathrm{TM}}$ for $0.001 \mathrm{~mol} / \mathrm{L}$ methylene blue was found to be the optimum amount which gave reproducible results.

\subsection{Glucose Analysis}

Concentrations of substrate in the anode chamber were analysed to ascertain microbial growth and biochemical activity. Samples were drawn at different intervals from the anodic chamber using a filter fitted syringe and analysed in YSI ${ }^{\mathrm{TM}} 2700$ biochemistry analyser. Figure 8 shows the change in glucose (substrate) concentration with time. The glucose concentration decreases with time and thus confirms the biochemical activity in the anodic chamber.

\subsection{Electrochemical Impedance Spectroscopy Analysis of the Fuel Cell}

The overall internal resistance in a MFC is comprised of ohmic resistance, charge transfer (polarization) resistance 


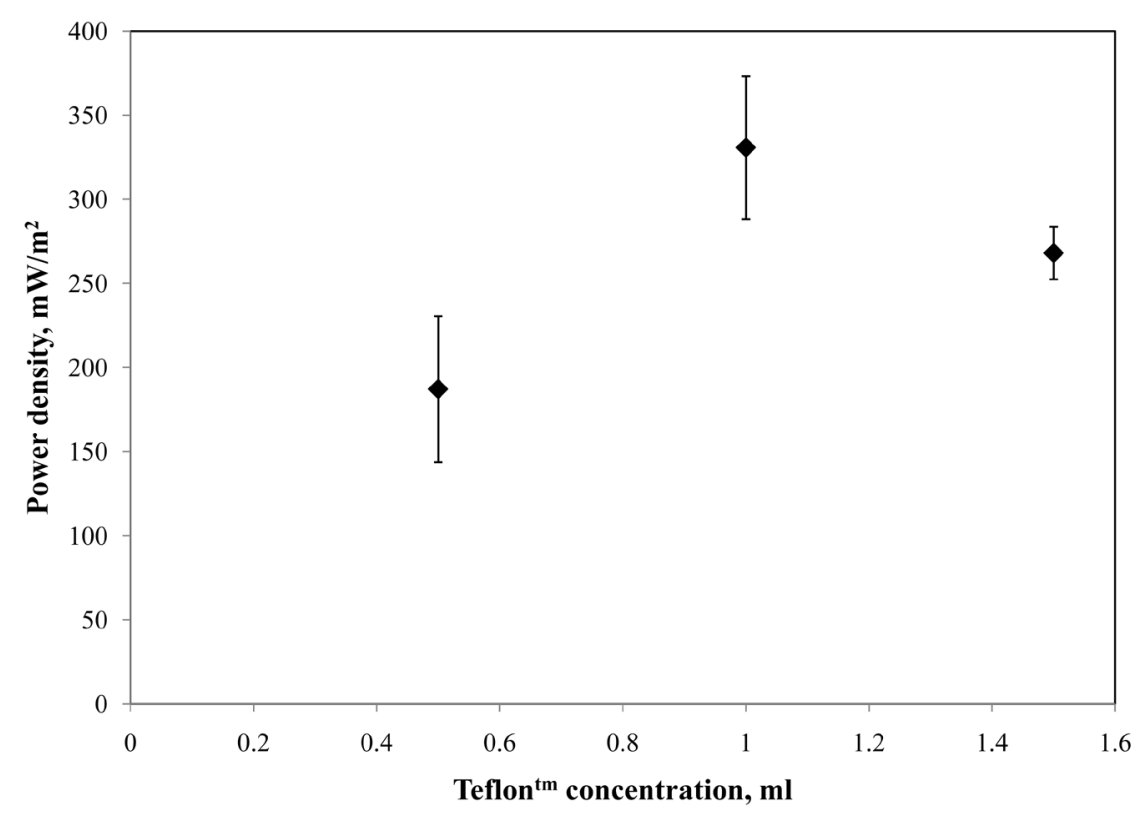

Figure 6. Effect of Teflon concentration on power density. Error bars represent standard deviation of power measurement [18].

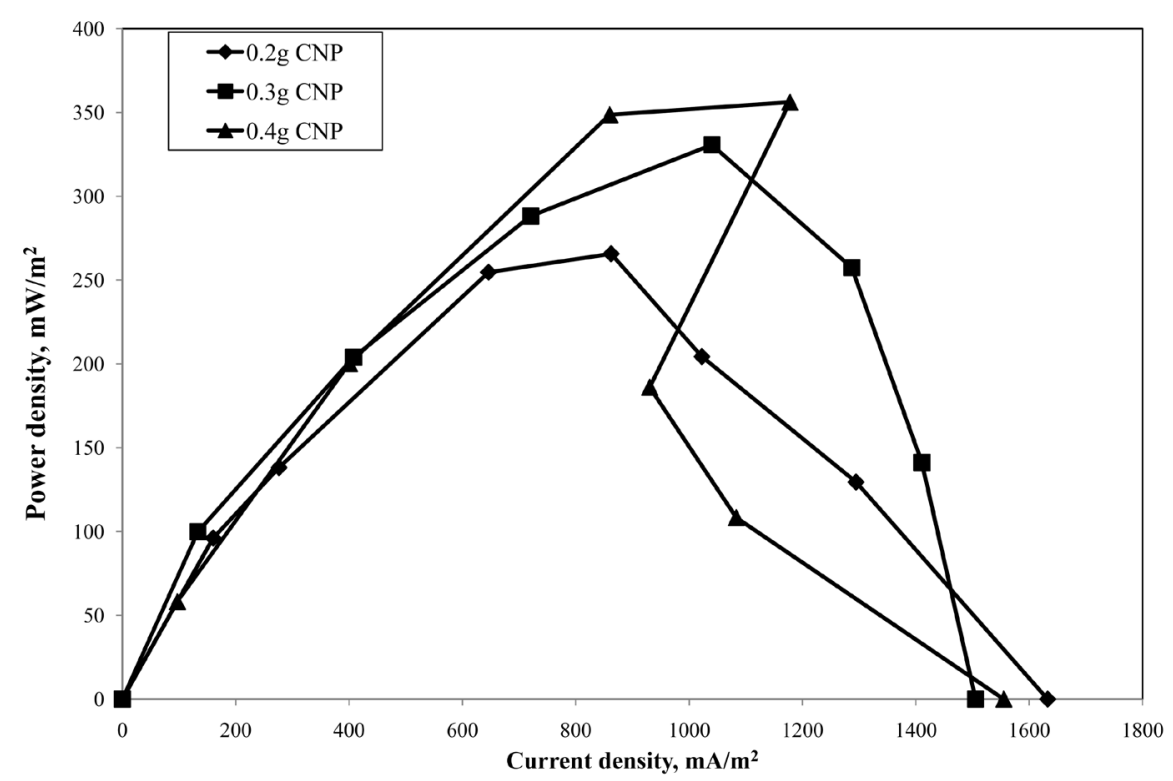

Figure 7. Effect of carbon nanoparticle concentration on bio-battery performance [18].

and diffusion resistance. Ohmic resistance constitutes the resistances of ion conduction through the anode solution, cathode solution and the proton exchange membrane. Charge transfer resistance constitutes the resistance of the transfer of charge between the electrodes and solution. In this case, for the anode, this includes the resistance due to microbial metabolism, charge transfer from the microbe to the mediator, and transfer from the mediator to the anode. Diffusion resistance constitutes the resistance caused by a build-up of concentration gradients within the MFC. Electrochemical Impedance Spectroscopy is commonly used for experimental studies of electrochemical phenomena, including corrosion processes; however, only recently, has EIS been used for determining the internal resistances involved in MFCs [17]. These EIS experiments must be conducted either at fixed potentials or the open circuit potentials [20] [22] [23].

Nyquist plots are used to represent the impedance data [20] [24]. While the Nyquist arc provides a qualitative 
analysis of the electrochemical polarization resistance, the quantitative values are obtained by fitting the data using equivalent circuits [23]. Figure 9 shows the nyquist plots obtained for two different anode configurations of the bio-battery. The first configuration incorporated a composite electrode with immobilized bacteria (CNPbacteria paste) and the second configuration incorporated a composite electrode with bacteria suspended in the solution. In the nyquist plots shown in Figure 9 the initial value on the real impedance axis represents the Ohmic resistance, and the diameter of the semicircle formed by the data immediately above the real axis corresponds to the charge transfer resistance [24]. The magnitude of the Nyquist curve for the first configuration incorporating a composite anode with immobilized bacteria (CNP-bacteria paste) was smaller than the second configuration that had a composite electrode with bacteria suspended in the solution.

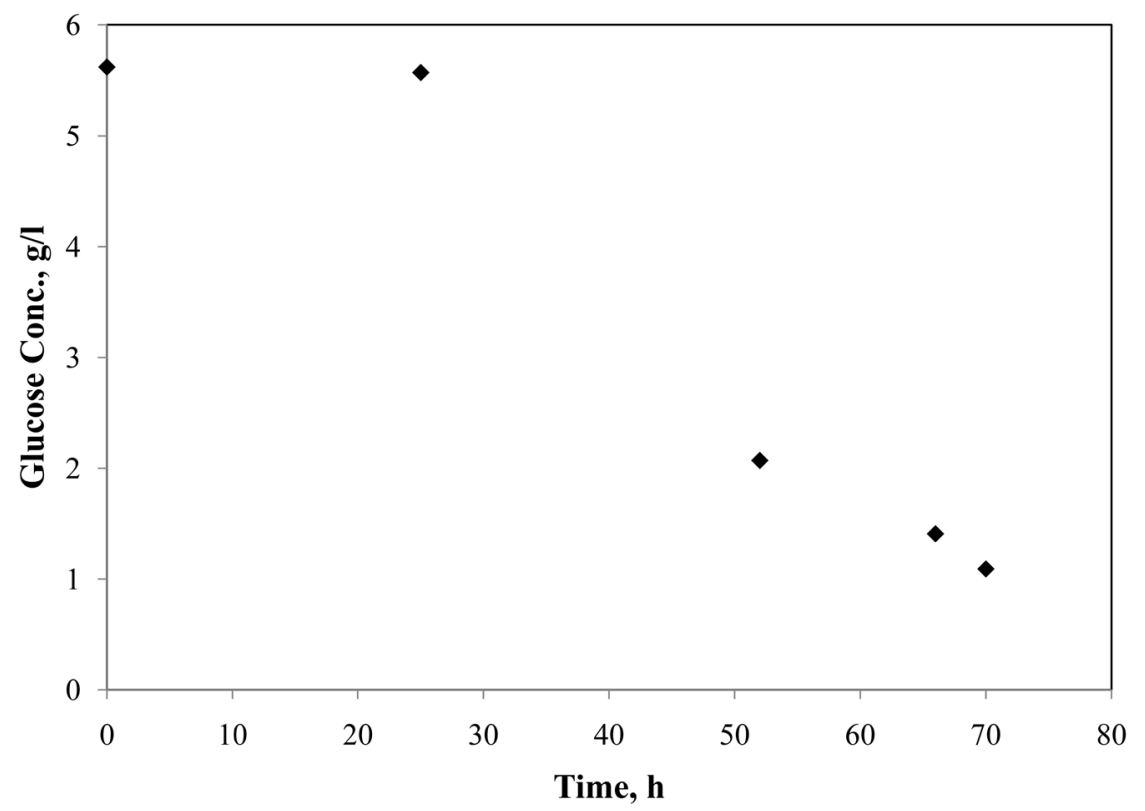

Figure 8. Glucose concentration in the anodic chamber [18].

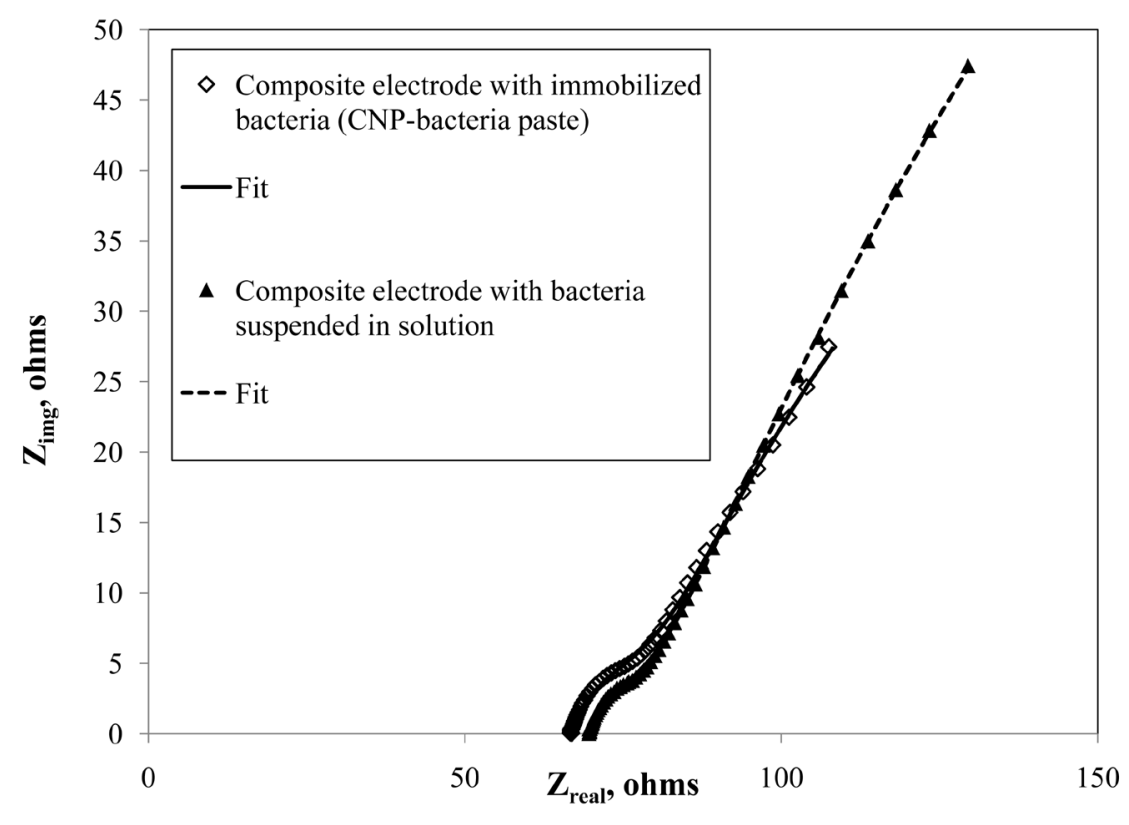

Figure 9. Nyquist plots for bio-batteries incorporating a composite electrode with immobilized bacteria and composite electrode with bacteria suspended in solution [18]. 
Analysis by fitting Nyquist data to the equivalent circuit revealed that the charge transfer resistance was significantly larger than both Ohmic resistance and diffusion resistance, with approximately $80 \%$ of the overall internal resistance, for both configurations. Figure 10 shows a comparison of the internal resistances in two MFCs with different configurations. The composite electrode with immobilized bacteria had a reduction in the overall charge transfer resistance by approximately $51 \%$. Additionally, it is also to be noted that there wasn't any significant difference in Ohmic and diffusion resistances between the two configurations. In fact, the diffusion resistance appears to be negligible in both the configurations, which is in accordance with previous research conducted using stainless steel electrodes with immobilized mediator (composite electrodes) [18]. Also, it was found that the charge transfer resistance of the anode $\left(R_{a}\right)$ was significantly higher than the cathode for both configurations, as shown in Table 1. This may be because of the oxidation process (by bacteria) at the anode being kinetically sluggish compared to the reduction process (ferricyanide) at the cathode [24]. Also, the $\mathrm{R}_{\mathrm{c}}$ value was similar for both configurations due to the use of the same catholyte (ferricyanide). The constant phase element of the anode $\left(\mathrm{Y}_{\mathrm{o}}\right)$ was also higher than the constant phase element of the cathode $\left(\mathrm{Y}_{\mathrm{oc}}\right)$, which could be due to the increase in surface area of the anode due to carbon nanoparticles [25]. Conversely, 95\% of the ohmic resistance was contributed by the proton exchange membrane, with the anodic chamber (anode and anolyte) contributing $3.6 \Omega$ and membrane contributing $62 \Omega$.

A check was conducted to confirm the values of internal resistance provided by the Gamry ${ }^{\mathrm{TM}}$ Echem Analyst software. From Figure 4, from the slope of the polarization curves, the average overall internal resistance for each bio-battery can be calculated. From these slopes it can be clearly seen that the overall internal resistance of the bio-battery incorporating a composite anode with bacteria suspended in solution is approximately double that of the bio-battery incorporating a composite anode with immobilized bacteria. These findings, from Figure 4 support the findings from the EIS analysis. These results demonstrate the improved charge transfer due to immobilization of the bacteria upon the composite anode.

\subsection{Comparison to Previous E. coli K-12 Based MFC Studies}

Modifications to electrodes incorporated into MFCs have been studied by various researchers and significant improvements in power densities following the addition of Carbon Nano Tubes CNT and Carbon nanoparticles (CNP) have been noted. However, due to the variations in electrode surface areas and difference in metabolism of different microorganisms, it can be difficult to directly compare the performance of MFC. The current study, focussing on composite electrodes with immobilized bacteria, achieved $1645 \mathrm{~mA} / \mathrm{m}^{2}$ of current and a power density of $378 \mathrm{~mW} / \mathrm{m}^{2}$. Table 2 shows a comparison of current study with other E. coli MFC studies. From Table 2, it can be seen that the configuration presented in this paper (composite anode with CNP-bacteria paste)

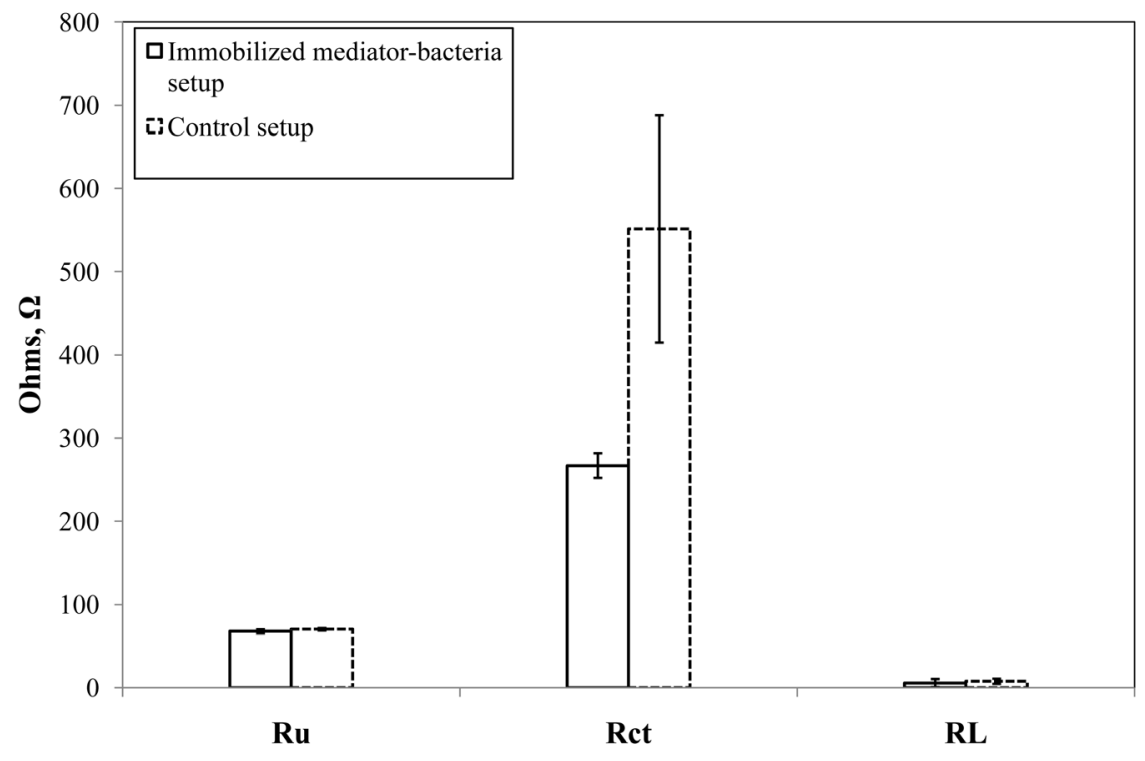

Figure 10. Internal resistances comparison of composite electrode with immobilized bacteria (CNP-bacteria paste) and composite electrode with bacteria suspended in solution [18]. 
Table 1. Electrochemical Impedance parameters of the cell with different anode configurations [18].

\begin{tabular}{ccccccc}
\hline Configuration & $\mathbf{R}_{\mathbf{u}}(\mathbf{\Omega})$ & $\mathbf{R}_{\mathbf{a}}(\mathbf{\Omega})$ & $\mathbf{R}_{\mathbf{c}}(\mathbf{\Omega})$ & $\mathbf{Y}_{\text {oa }}\left(\mathbf{S} * \mathbf{s}^{\mathrm{a}}\right)$ & $\mathbf{Y}_{\text {oc }}\left(\mathbf{S} * \mathbf{s}^{\mathrm{a}}\right)$ & $\mathbf{a}$ \\
\hline $\begin{array}{c}\text { Composite electrode with immobilized } \\
\text { bacteria (CNP-bacteria paste) }\end{array}$ & 66.53 & $\mathbf{1 6 9}$ & $\mathbf{1 1 . 9 5}$ & 0.027 & 0.00456 & 0.580 \\
$\begin{array}{c}\text { Composite electrode with bacteria } \\
\text { suspended in solution (control setup) }\end{array}$ & 69.32 & $\mathbf{4 5 5}$ & $\mathbf{9 . 0 9 2}$ & 0.0165 & 0.00347 & 0.546 \\
\hline
\end{tabular}

Table 2. Comparison of current study with studies from the open literature that used E. coli as anode catalyst with electrode modifications [18].

\begin{tabular}{ccccccc}
\hline $\begin{array}{c}\text { Comparison } \\
\text { parameter }\end{array}$ & $\begin{array}{c}\text { Current } \\
\text { study }\end{array}$ & $\begin{array}{c}\text { Ming et al. } \\
\mathbf{2 0 0 8}[8]\end{array}$ & $\begin{array}{c}\text { Qiao et al., } \\
\mathbf{2 0 0 7}[7]\end{array}$ & $\begin{array}{c}\text { Park et al., } \\
\mathbf{2 0 0 3}[11]\end{array}$ & $\begin{array}{c}\text { Park et al., } \\
\mathbf{2 0 0 0}[13]\end{array}$ & $\begin{array}{c}\text { Davilla et al., Hoffman et al., } \\
\text { 2008 [12] }\end{array}$ \\
\hline $\begin{array}{c}\text { Max current } \\
\text { density, mA } / \mathrm{m}^{2}\end{array}$ & $\mathbf{1 6 4 5}$ & 330.75 & $\sim 145$ & 325 & 31 & - \\
$\begin{array}{c}\text { Max power density, } \\
\text { mW/m }\end{array}$ & $\mathbf{3 7 8}$ & 106.68 & 42 & 91 & - & 7.89 \\
\hline
\end{tabular}

displays improved current and power densities when compared with other values from the literature [3] [7] [8] [11]-[13]. This improvement could be attributed to the immobilization of the mediator and bacteria directly on the surface of the electrode and enhanced conductivity by the carbon nanoparticles.

\section{Conclusions}

The composite electrodes with immobilized bacteria (Escherichia coli K-12) achieved maximum current and power densities of $1645 \mathrm{~mA} / \mathrm{m}^{2}$ and $378 \mathrm{~mW} / \mathrm{m}^{2}$, respectively, when incorporated into the anodic chamber of a bio-battery. The current and power densities of this electrode were almost $53 \%$ and $69 \%$ more than other configurations, which could be attributed to the reduced charge transfer resistance in the bio-battery. Specifically, it was concluded that the immobilization of bacteria onto the anode decreased the resistance to the transfer of charge from the bacteria to anode by approximately 50\%, when compared to bacteria suspended in solution. These findings were confirmed through an Electrochemical Impedance Spectroscopy analysis with model fitting. This model also showed that the charge transfer, from bacteria to anode, is the most significant component of the overall bio-battery internal resistance.

It was also determined that the carbon nanoparticles aided electron transfer. The technique of bacteria immobilization presented in this paper did not inhibit bacterial growth. This was confirmed by the glucose analysis experiment for biochemical activity. The composite electrode with immobilized bacteria presents itself as a promising candidate to be employed as cost effective and high performing anode in Microbial Fuel Cells and bio-batteries.

\section{Acknowledgements}

The authors gratefully acknowledge Dawn Giesbrecht, Royal University Hospital, University of Saskatchewan, Canada.

\section{Funding}

Financial support was provided by the Natural Science and Engineering Research Council of Canada (NSERC).

\section{References}

[1] Rabaey, K. and Verstraete, W. (2005) Microbial Fuel Cells: Novel Biotechnology for Energy Generation. Trends in Biotechnology, 23, 291-298. http://dx.doi.org/10.1016/j.tibtech.2005.04.008

[2] Logan, B.E., Hamelers, B., Rozendal, R., Schröder, U., Keller, J., Freguia, S., Aelterman, P., Verstraete, W. and Rabaey, K. (2006) Microbial Fuel Cells: Methodology and Technology. Environmental Science \& Technology, 40, 5181- 
5192. http://dx.doi.org/10.1021/es0605016

[3] Yuan, Y., Jeon, Y., Ahmed, J., Park, W. and Kim, S. (2009) Use of Carbon Nanoparticles for Bacteria Immobilization in Microbial Fuel Cells for High Power Output. Journal of the Electrochemical Society, 156, B1238-B1241. http://dx.doi.org/10.1149/1.3190477

[4] Kim, J.H., Park, W. and Kim, S. (2011) Immobilized Polyviologen as an Effective Redox Mediator for Microbial Fuel Cells. Bulletin of the Korean Chemical Society, 32, 3849-3850. http://dx.doi.org/10.5012/bkcs.2011.32.11.3849

[5] Prieto-Simón, B. and Fàbregas, E. (2004) Comparative Study of Electron Mediators Used in the Electrochemical Oxidation of Nadh. Biosensors and Bioelectronics, 19, 1131-1138. http://dx.doi.org/10.1016/j.bios.2003.10.010

[6] Qiao, Y., Li, C.M., Bao, S.-J. and Bao, Q.-L. (2007) Carbon Nanotube/Polyaniline Composite as Anode Material for Microbial Fuel Cells. Journal of Power Sources, 170, 79-84. http://dx.doi.org/10.1016/j.jpowsour.2007.03.048

[7] Xi, M.-Y. and Sun, Y.-P. (2008) Preliminary Study on E. coli Microbial Fuel Cell and On-Electrode Taming of the Biocatalyst. The Chinese Journal of Process Engineering, 8.

[8] Aelterman, P., Versichele, M., Marzorati, M., Boon, N. and Verstraete, W. (2008) Loading Rate and External Resistance Control the Electricity Generation of Microbial Fuel Cells with Different Three-Dimensional Anodes. Bioresource Technology, 99, 8895-8902. http://dx.doi.org/10.1016/j.biortech.2008.04.061

[9] Wang, X., Cheng, S., Feng, Y., Merrill, M.D., Saito, T. and Logan, B.E. (2009) Use of Carbon Mesh Anodes and the Effect of Different Pretreatment Methods on Power Production in Microbial Fuel Cells. Environmental Science \& Technology, 43, 6870-6874. http://dx.doi.org/10.1021/es900997w

[10] Park, D.H. and Zeikus, J.G. (2003) Improved Fuel Cell and Electrode Designs for Producing Electricity from Microbial Degradation. Biotechnology and Bioengineering, 81, 348-355. http://dx.doi.org/10.1002/bit.10501

[11] Davila, D., Esquivel, J., Vigues, N., Sanchez, O., Garrido, L., Tomas, N., Sabate, N., Del Campo, F., Munoz, F. and Mas, J. (2008) Development and Optimization of Microbial Fuel Cells. Journal of New Materials for Electrochemical Systems, 11, 99.

[12] Park, D.H., Kim, S.K., Shin, I.H. and Jeong, Y.J. (2000) Electricity Production in Biofuel Cell Using Modified Graphite Electrode with Neutral Red. Biotechnology Letters, 22, 1301-1304. http://dx.doi.org/10.1023/A:1005674107841

[13] Zhang, F., Saito, T., Cheng, S., Hickner, M.A. and Logan, B.E. (2010) Microbial Fuel Cell Cathodes with Poly(dimethylsiloxane) Diffusion Layers Constructed around Stainless Steel Mesh Current Collectors. Environmental Science \& Technology, 44, 1490-1495. http://dx.doi.org/10.1021/es903009d

[14] Dumas, C., Mollica, A., Féron, D., Basséguy, R., Etcheverry, L. and Bergel, A. (2007) Marine Microbial Fuel Cell: Use of Stainless Steel Electrodes as Anode and Cathode Materials. Electrochimica Acta, 53, 468-473. http://dx.doi.org/10.1016/j.electacta.2007.06.069

[15] Hoffman, A.B., Suresh, S., Evitts, R.W., Kennell, G.F. and Godwin, J.M. (2013) Dual-Chambered Bio-Batteries Using Immobilized Mediator Electrodes. Journal of Applied Electrochemistry, 43, 629-636. http://dx.doi.org/10.1007/s10800-013-0550-5

[16] Yuan, Y., Ahmed, J., Zhou, L., Zhao, B. and Kim, S. (2011) Carbon Nanoparticles-Assisted Mediator-Less Microbial Fuel Cells Using Proteus vulgaris. Biosensors and Bioelectronics, 27, 106-112. http://dx.doi.org/10.1016/j.bios.2011.06.025

[17] Godwin, J.M. and Evitts, R. (2011) Polypyrrole/Poly(methylene blue) Composite Electrode Films on Stainless Steel. ECS Transactions, 33, 181-188. http://dx.doi.org/10.1149/1.3565513

[18] Godwin, J. (2011) Immobilized Mediator Electrodes for Microbial Fuel Cells. Master’s Thesis, University of Saskatchewan, Saskatoon.

[19] Suresh, S. (2014) Composite Electrodes with Immobilized Bacteria Bioanode and Photosynthetic Algae Biocathode for Bio-Batteries. Master's Thesis, University of Saskatchewan, Saskatoon.

[20] He, Z. and Mansfeld, F. (2009) Exploring the Use of Electrochemical Impedance Spectroscopy (Eis) in Microbial Fuel Cell Studies. Energy \& Environmental Science, 2, 215-219. http://dx.doi.org/10.1039/B814914C

[21] Manohar, A.K., Bretschger, O., Nealson, K.H. and Mansfeld, F. (2008) The Use of Electrochemical Impedance Spectroscopy (Eis) in the Evaluation of the Electrochemical Properties of a Microbial Fuel Cell. Bioelectrochemistry, 72, 149-154. http://dx.doi.org/10.1016/j.bioelechem.2008.01.004

[22] He, Z., Minteer, S.D. and Angenent, L.T. (2005) Electricity Generation from Artificial Wastewater Using an Upflow Microbial Fuel Cell. Environmental Science \& Technology, 39, 5262-5267. http://dx.doi.org/10.1021/es0502876

[23] Barsoukov, E. and Macdonald, J.R. (2005) Impedance Spectroscopy: Theory, Experiment, and Applications. Wiley-Interscience, Hoboken. 
[24] Ramasamy, R.P., Ren, Z., Mench, M.M. and Regan, J.M. (2008) Impact of Initial Biofilm Growth on the Anode Impedance of Microbial Fuel Cells. Biotechnology and Bioengineering, 101, 101-108. http://dx.doi.org/10.1002/bit.21878

[25] Hosseini, M.G. and Ahadzadeh, I. (2012) A Dual-Chambered Microbial Fuel Cell with Ti/Nano-Tio2/Pd Nano-Structure Cathode. Journal of Power Sources, 220, 292-297. http://dx.doi.org/10.1016/j.jpowsour.2012.07.096 